\title{
Endodontic Management of Mandibular First Molars with Three Distal Root Canals-A Report of Two Cases
}

\author{
Al-Hawwas Abdullah Yousef ${ }^{1}$, Al-Dahman Yousef Hamad ${ }^{2}$, Aldosary Khalid M ${ }^{3}$, Al-Dakheel Majed D³ , Al-Zuhair \\ Hind $^{4}$ and Al-Jebaly Asma Suliman ${ }^{4}$ \\ ${ }^{1}$ Endodontist, Head of Endodontic Division, Dental Department, King Abdulaziz University Hospital, King Saud University, Riyadh, Kingdom of Saudi \\ Arabia \\ ${ }^{2}$ Endodontist, Ministry of Health, Kingdom of Saudi Arabia
}

${ }^{3}$ Consultant in Restorative Dentistry, King Saud University Medical City, Riyadh, Kingdom of Saudi Arabia

${ }^{4}$ General Practitioner, Riyadh, Kingdom of Saudi Arabia

Submission:June 28, 2018 Published: August 28, 2018

*Corresponding author: Yousef Hamad Al-Dahman, Endodontist, Ministry of Health, P. 0. Box: 84891, Riyadh 11681, Kingdom of Saudi Arabia, Email: yousef.aldahman@gmail.com

\section{Abstract}

The proper knowledge of root canal anatomy of teeth and its variation is necessary for successful endodontic treatment. Permanent mandibular first molars are usually having two mesial canals and one or two distal canals. Moreover, middle mesial canal was present in different case reports in the literature. However, the presence of three distal canals in distal root is rare. This paper describes two case reports of root canal therapy of permanent mandibular molars with three distal root canals.

Keywords: Root canal anatomy; Mandibular molar; Root canal treatment

\section{Introduction}

The knowledge of the anatomy of root canal system and its morphological variations play a significant role in all the steps of endodontic treatment [1]. Therefore, the clinician should have a thorough understanding of the detailed anatomy of the root canal to be able to utilize the most appropriate treatment techniques and protocols and thereby increasing the percentage of success rate [2].

Generally, mandibular molars have a complex and varying morphology [3]. The mandibular first molars usually have two roots (mesial and distal) which have two mesial and one or two distal canals, respectively [1].

Rarely, there is an extra canal called middle mesial (MM) in the mesial root with an incidence ranged from $0 \%$ to $46 \%$ [4-8]. Moreover, middle distal (MD) canal may present in the distal root with an incidence up to 8\% [9]. Additionally, cases of mandibular molars with seven and eight root canals have been reported in the literature $[10,11]$. Other anatomical variations include radix entomolaris, radix paramolaris, C-shaped canal, and taurodontism [12-15].

Different techniques have been used and described in the literature for evaluation of anatomical variations of the first mandibular molar including plastic resin injection [4], endodontic access and radiographs with files into root canals [16], retrospective evaluation of radiographs [17], clearing of samples with and without ink injection $[18,19]$, sectioning and macroscopic or scanning electron microscopy (SEM) evaluation $[20,21]$, computed tomography (CT) [20], spiral computed tomography (SCT) [22], micro-computed tomography ( $\mu$-CT) [23], and cone-beam computed tomography (CBCT) [24]. The present case report describes a successful endodontic management of two cases of mandibular first molar with 3 distal canals.

\section{Case Reports}

\section{Case 1}

A 24-year-old Saudi female patient with a noncontributing medical history was referred to endodontic department of Prince Sultan Military Medical City, Riyadh, Saudi Arabia, for root canal treatment of mandibular rightfirstmolar (\#46). The chief complaint was to complete the root canal treatment which was previously initiated by a general practitioner. Clinical examinations revealed a temporary restoration on tooth \#46, in addition to sensitivity on percussion and unremarkable findings with palpation, and normal probing depth with no mobility. Radiographic examination revealed a coronal radio-opaque temporary filling, previously initiated root canal treatment, one metallic object resembling an endodontic file situated in the intracanal space of one of the mesial canals and a periapical radiolucency in both mesial and distal roots (Figure 1a). Based on the clinical and radiographic findings and according to American Association of Endodontics consensus [25], the tooth was diagnosed as previously initiated root canal treatment with symptomatic apical periodontitis. 
Local anesthesia was administered with $2 \%$ lidocaine and 1:100000 epinephrine, and treatment was initiated under rubber dam isolation. The temporary restoration was removed, and access was gained to the pulp chamber. After endodontic access preparation, the pulpal floor was inspected under magnification loupes 5.5x (PrismPro Line Loupes, SurgiTel, MI, USA). Two separate mesial and two separate distal canals were identified. On careful examination of distal canals, one additional canal orifice [Middle Distal (MD)] was identified in the center of the groove and situated between the distobuccal (DB) and the distolingual (DL) canal orifices.

With the aid of the same magnification loupes, a separated instrument was confirmed in the middle portion of the MB canal. Coronal flaring was achieved with size \#3 and \#4 Gates-Glidden drills (Dentsply Maillefer, Ballaigues, Switzerland) to establish straight line access. 5.25\% sodium hypochlorite $(\mathrm{NaOCl})$ irrigating solution was used to irrigate the MB canal and Glyde (Dentsply, Maillefer, Ballaigues, Switzerland) was used as a canal lubricant. Unfortunately, the instrument was located beyond a curvature and attempts failed to remove it, so it was bypassed successfully starting with a \#8 followed by \#10 then \#15 K-flex files (Kerr Manufacturing Co., Romulus, MI). Other canals were negotiated using \#15 K-flex files.

Then, the working length was established using Root ZX II (J. Morita, Tokyo, Japan) electronic apex locator and confirmed radiographically (Figure $1 \mathrm{~b} \& 1 \mathrm{c}$ ). After finalizing the access cavity (Figure 1d), the root canals were prepared using K3 Rotary System (SybronEndo, Orange, CA, USA) to size 300.06 taper for all canals. Copious irrigation with $\mathrm{NaOCl} 5.25 \%$ followed by $17 \%$ ethylenediaminetetraacetic acid (EDTA) was carried out during the instrumentation phase. After the final flush, root canals were dried with paper points (Maillefer, Dentsply, Ballaigues, Switzerland) and obturated with gutta-percha and AH26 sealer (Dentsply, Maillefer, Switzerland) using cold lateral compaction technique (Figure 1e). The access cavity was sealed with Fuji resin-modified glass ionomer filling material (ChemFil, Dentsply DeTrey, Germany) (Figure 1f \& 1g). Follow-up has been made in 6 months (Figure $1 \mathrm{~h} \& \mathrm{1i}$ ). The tooth was asymptomatic, and the size of the periapical radiolucency was decreased.

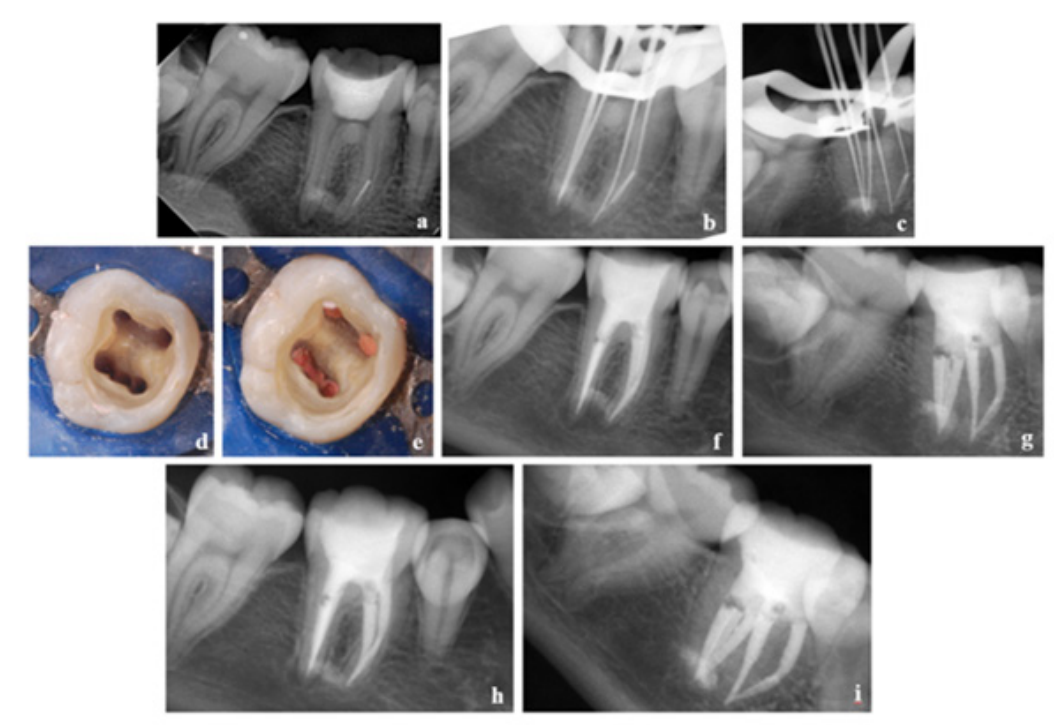

Figure 1: (a) Preoperative radiograph with a separated instrument in the mesial root. (b): Working length determination. (c): Angled radiograph confirming the presence of three distal canals and position of the separated instrument in the mesiobuccal canal. The separated instrument was bypassed. (d): Clinical picture of the pulp chamber floor. (e): Clinical picture of the pulp chamber floor after obturation. (f): Postoperative radiograph with the tooth having final restoration. (g): Postoperative angled radiograph. (h): 6-months follow-up radiograph. (i): 6-months follow-up angled radiograph

\section{Case 2}

A 40-year-old Saudi female patient with no history of any systematic disease was presented to the endodontic clinic in King Abdulaziz University Hospital, Riyadh, Saudi Arabia with a history of lingering pain for the past couple of days in relation to mandibular left first molar tooth (\#36). Clinical examinations revealed a sealed composite restoration, no associated swelling nor sinus tract, but the tooth was tender to vertical percussion with normal probing depth and asymptomatic to palpation.
Pulp sensibility test (Endo-ice, The Hygienic Corporation, Akron, $\mathrm{OH}, \mathrm{USA}$ ) showed intense pain that did not subside rapidly. Radiographic evaluation revealed a coronal radio-opaque composite restoration with periapical radiolucency in the mesial root (Figure 2a). Based on the clinical and radiographic examinations, the tooth was diagnosed as having a symptomatic irreversible pulpitis with symptomatic apical periodontitis.

Cone-beam computed tomography (CBCT) was carried out using three-dimensional (3D) Accuitomo scanner (J. Morita, 
Kyoto, Japan), with Viewer Plus software (J. Morita, Japan), which produced a smallest field of view images, to reduce the radiation dosage. CBCT images revealed two roots and five canals, two mesial and three distal (Figure 2b). A nonsurgical root canal treatment was planned accordingly.

The patient received local anesthesia with $2 \%$ Lidoocaine and 1:100000 epinephrine, and the rubber dam was placed. Following the removal of composite filling, careful examination of the pulpal floor under dental operating microscope (DOM) (OPMI, Carl Zeiss Meditec, Germany) revealed two mesial canals and three separate distal canal orifices (distobuccal, middle distal, and distolingual).

Coronal flaring was achieved with size \#3 and \#4 GatesGlidden drills to establish straight line access (Figure 2c), and the working length was established using Root ZX II. After that, root canals were prepared using Twisted File Adaptive (TF-Adaptive) System (SybronEndo, Orange, CA, USA) up to size 350.06 for all canals, and copious irrigation with $5.25 \% \mathrm{NaOCl}$ and $17 \%$ EDTA solution was carried out during the root canal preparation phase. Master cones were adjusted according to the working length and a radiograph was taken (Figure $2 \mathrm{~d}$ ). All canals were dried with paper points and then filled with gutta-percha and AH26 sealer using cold lateral compaction technique followed by thermomechanical compaction. Finally, the access cavity was filled with Coltosol temporary filling material (Coltosol@ F, Coltene, Switzerland) and the patient was referred to receive final restoration (Figure 2e \& 2f). The patient was scheduled for a follow-up appointment after 6 months, but unfortunately, she missed her appointment.

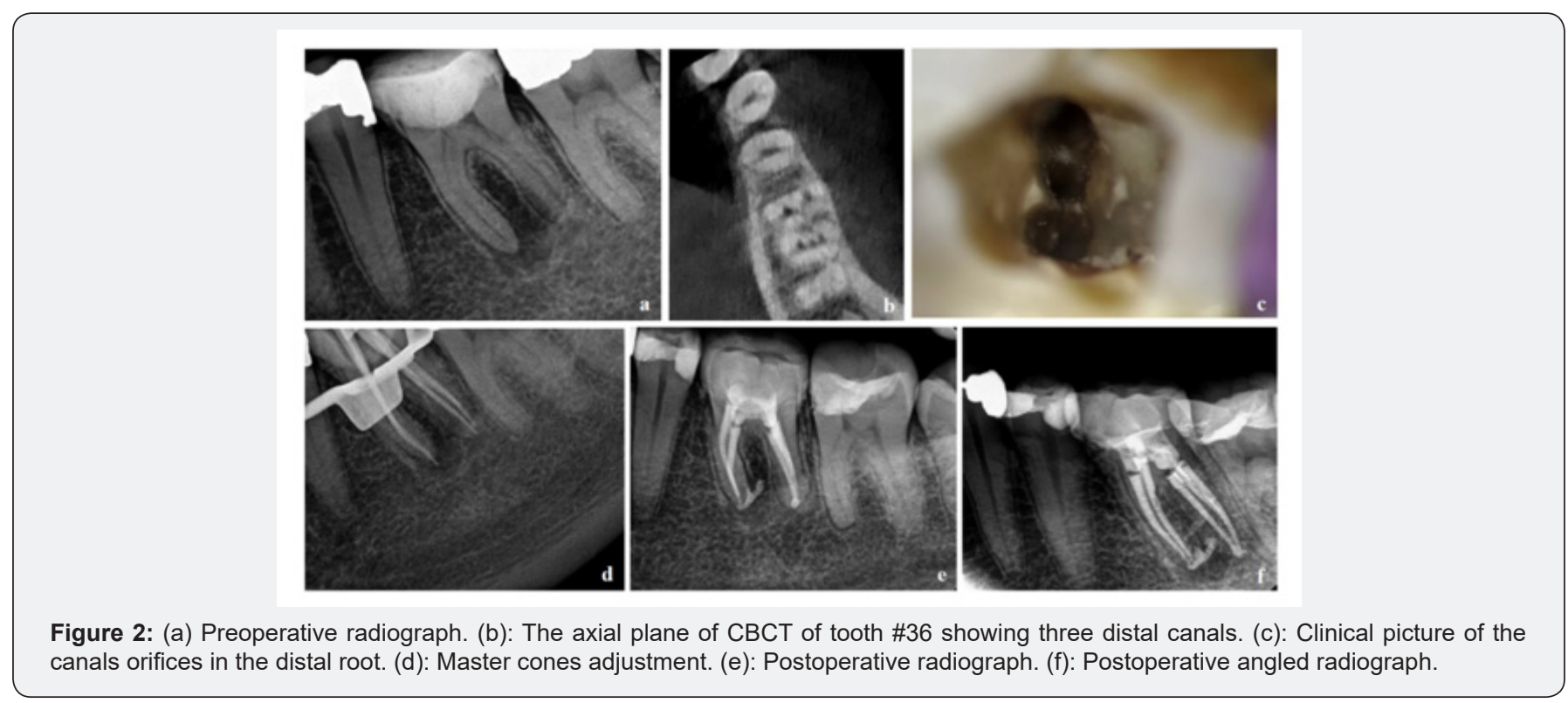

\section{Discussion}

Adequate root canal therapy requires locating, shaping, cleaning, and obturating all root canal system to prevent posttreatment disease, pain, and/or complications of endodontically treated tooth [26].

Different teeth morphological variations exist which make the root canal treatment more challenging. Therefore, the clinician must be familiar with such variations and use the available tools to negotiate and treat the root canal system and improve the treatment outcomes $[27,28]$.

The presence of an extra canal in the distal root of mandibular first molar is called middle distal canal. The prevalence of a middle distal canal had been reported to range from $0-3 \%$ in different ethnic groups [18,19,21,29-35].

In a recent study by Filpo-Perez et al. in Brazilian population using $\mu$-CT analysis, the prevalence of one canal in the distal root of mandibular first molar was in $76 \%$, two canals in $13 \%$, three canals in $8 \%$, and four canals in $3 \%$ of the samples [9].
Moreover, several case reports of mandibular first molar with more than two canals in the distal root have been existed in the literature [10,36-51]. In this report, the two cases were having one distal root with three root canals, which were similar in the morphological variations to the previous reported cases $[27,36,38,41,43,46-48,50,51]$.

Conventional periapical radiographs taken in different angulations is necessary to aid in detection of any morphological variations of root canal anatomy of teeth [52]. If this technique fails in the detection, CBCT can be used which help in better detection of such variations [53]. In the first case, different angled periapical radiographs were able to detect the morphological variations, while in the second case, CBCT was taken which aid in the detection of root canal anatomy and management of the treated tooth.

Root-filled teeth with a retained separated instrument had no effect on treatment outcome [54], while a lower healing rate was reported in other studies [55]. In case \#1, the separated instrument in MB canal was bypassed which facilitate shaping and 
cleaning procedures of the root canal, and this led to the decrease in periapical lesion during the follow-up visit.

Furthermore, the use of magnification tools in endodontics by the means of magnifying loupes and DOM will aid in the proper inspection of the pulp chamber floor and detecting these variations which could not be seen easily by naked eyes [56]. The first case was managed under magnifying loupes, while the second case was managed under DOM, which enhanced the exploration of the floor of the pulpal floor and detection of canal orifices.

\section{Conclusion}

The clinician should be aware of the variable anatomical variations of mandibular molars. It is important to utilize all the available diagnostic tools to find and treat the whole root canal system. Moreover, the proper knowledge of root canal anatomy, angled periapical radiographs, good access cavity preparation, proper exploration of pulpal floor under magnification, and CBCT analysis are important prerequisites for a successful treatment outcome.

\section{References}

1. Vertucci FJ (1984) Root canal anatomy of the human permanent teeth. Oral Surgery Oral Medicine Oral Pathology 58(5): 589-599.

2. Jou YT, Karabucak B, Levin J, Liu D (2004) Endodontic working width: current concepts and techniques. Dent Clin North Am 48(1): 323-335.

3. Mannocci F, Peru M, Sherriff M, Cook R, Pitt Ford T (2005) The isthmuses of the mesial root of mandibular molars: A micro-computed tomographic study. Int Endod J 38(8): 558-563.

4. Skidmore AE, Bjorndal AM (1971) Root canal morphology of the human mandibular first molar. Oral Surg Oral Med Oral Pathol 32(5): 778-784.

5. Azim AA, Deutsch AS, Solomon CS (2015) Prevalence of middle mesial canals in mandibular molars after guided troughing under high magnification: An in vivo investigation. J Endod 41(2): 164-168.

6. Nosrat A, Deschenes RJ, Tordik PA, Hicks ML, Fouad AF (2015) Middle mesial canals in mandibular molars: Incidence and related factors. J Endod 41(1): 28-32.

7. de Toubes KM, Côrtes MI, Valadares MA, Fonseca LC, Nunes E, et al. (2012) Comparative analysis of accessory mesial canal identification in mandibular first molars by using four different diagnostic methods. J Endod 38(4): 436-441.

8. Karapinar-Kazandag M, Basrani BR, Friedman S (2010) The operating microscope enhances detection and negotiation of accessory mesial canals in mandibular molars. J Endod 36(8): 1289-1294.

9. Filpo-Perez C, Bramante CM, Villas-Boas MH, Húngaro Duarte MA, Versiani MA, et al. (2015) Micro-computed tomographic analysis of the root canal morphology of the distal root of mandibular first molar. J Endod 41(2): 231-236.

10. Reeh ES (1998) Seven canals in a lower first molar. J Endod 24(7): 497 499.

11. Arora A, Acharya SR, Sharma P (2015) Endodontic treatment of a mandibular first molar with 8 canals: A case report. Restor Dent Endod 40(1): 75-78.

12. De Moor RJ, Deroose CA, Calberson FL (2004) The radix entomolaris in mandibular first molars: An endodontic challenge. Int Endod J 37(11): 789-799.

13. Carlsen O, Alexandersen V (1991) Radix paramolaris in permanent mandibular molars: Identification and morphology. Scan J Dent Res 99(3): 189-195.
14. Cooke HG, Cox FL (1979) C-shaped canal configurations in mandibular molars. J Am Dent Assoc 99(5): 836-839.

15. Saini T, Wilson CA (1990) Taurodont molars: Review of literature and radiological features. Saudi Dent J 2(2): 68-70.

16. Pineda F, Kuttler Y (1972) Mesiodistal and buccolingual roentgenographic investigation of 7,275 root canals. Oral Surg Oral Med Oral Pathol 33(1): 101-110.

17. Badanelli Marcano P, Martinez-Berna A (1983) Surgical preparation of root canals. Rev Esp Endodoncia 1(2): 61-77.

18. Gulabivala K, Aung TH, Alavi A, Ng YL (2001) Root and canal morphology of Burmese mandibular molars. Int Endod J 34(5): 359-370.

19. Ahmed HA, Abu-bakr NH, Yahia NA, Ibrahim YE (2007) Root and canal morphology of permanent mandibular molars in a Sudanese population. Int Endod J 40(10): 766-771.

20. Navarro LF, Luzi A, García AA, García AH (2007) Third canal in the mesial root of permanent mandibular first molars: review of the literature and presentation of 3 clinical reports and 2 in vitro studies. Med Oral Patol Oral Cir Bucal 12(8): E605-E609.

21. Sperber GH, Moreau JL (1998) Study of the number of roots and canals in Senegalese first permanent mandibular molars. Int Endod J 31(2): 117-122.

22. Sachdeva GS, Ballal S, Gopikrishna V, Kandaswamy D (2008) Endodontic management of a mandibular second premolar with four roots and four root canals with the aid of spiral computed tomography: a case report. J Endod 34(1): 104-107.

23. Gu L, Wei X, Ling J, Huang X (2009) A microcomputed tomographic study of canal isthmuses in the mesial root of mandibular first molars in a Chinese population. J Endod 35(3): 353-356.

24. Durack C, Patel S (2012) Cone-beam computed tomography in endodontics. Braz Dent J 23(3): 179-191.

25. Glickman GN (2009) AAE consensus conference on diagnostic terminology: Background and perspectives. Journal of Endodontics 35(12): 1619-1620.

26. Sjögren U, Hagglund B, Sundqvist G, Wing K (1990) Factors affecting the long-term results of endodontic treatment. J Endod 16(10): 498504.

27. Bansal P, Nikhil V, Shekhar S (2015) Three distal root canals in mandibular first molar with different canal configurations: Report of two cases and literature review. Saudi Endodontic Journal 5(1): 51-55.

28. Al-Dahman YH, Al-Qahtani SA, Al-Mahdi AA, Al-Hawwas AY (2018) Endodontic management of mandibular premolars with three root canals: Case series. Saudi Endodontic Journal 8(2): 133-138.

29. Calistkan MK, Pehlivan Y, Sepetciogu F, Turkun M, Tuncer SS (1995) Root canal morphology of human permanent teeth in a Turkish population. J Endod 21(4): 200-204.

30. Goel NK, Gill KS, Taneja JR (1991) Study of root canal configuration in mandibular first permanent molar. J Indian Soc Pedod Prev Dent 8(1): $12-14$.

31. Gulabivala K, Opasanon A, Ng YL, Alavi A (2002) Root canal morphology of Thai mandibular molars. Int Endod J 35(1): 56-62.

32. Sert S, Aslanalp V, Tanalap J (2004) Investigation of the root canal configurations of mandibular permanent teeth in the Turkih population. Int Endod J 37(7): 494-499.

33. Al-Qudah AA, Awawdeh LA (2009) Root and canal morphology of mandibular first and second molar teeth in a Jordanian population. Int Endod J 42(9): 775-784.

34. Reuben J, Velmurugan N, Kandaswamy D (2008) The evaluation of root canal morphology of the mandibular first molar in an indian population using spiral computed tomography scan: An in vitro study. J Endod 34(2): 212-215. 
35. Martinez-Berna A, Badanelli P (1985) Mandibular first molar with six root canals. Journal of Endodontics 11(8): 348-352.

36. Ghoddusi J, Naghavi N, Zarei M, Rohani E (2007) Mandibular first molar with four distal canals. J Endod 33(12): 1481-1483.

37. Berthiaume JT (1983) Five canals in a lower first molar. Journal of Michigan Dental Association 65: 213-214.

38. Stroner WF, Remeikis NA, Carr GB (1984) Mandibular first molar with three distal canals. Oral Surg Oral Med Oral Pathol 57(5): 554-557.

39. Beatty RG, Interian CM (1985) A mandibular first molar with five canals: Report of case. Journal of American Dental Association 111(5): 769-771.

40. Quackenbush LE (1986) Mandibular molar with three distal root canals. Endodontic Dental Traumatology 2(1): 48-49.

41. Friedman S, Moshonov J, Stabholz A (1986) Five root canal in a mandibular first molar. Endodontic Dental Traumatology 2(5): 226-228.

42. Kimura Y, Matsumoto K (2000) Mandibular first molar with three root canals. International Endodontic Journal 33: 468-470.

43. Barletta FB, Dotto SR, Reis Mde S, Ferreira R, Travasos RM (2008) Mandibular molar with five root canals. Australian Endodontic Journal 34: 129-132.

44. Chandra SS, Rajasekaran M, Shanker P, Indira R (2009) Endodontic management of a mandibular first molar with three distal canals confirmes with the aid of spiral computerized tomography: A case reportOral Surg Oral Med Oral Pathol Oral Radiol Endod 108(4): e77e81.

45. Kottoor J, Sudha R, Velmurugan N (2010) Middle distal canal of the mandibular first molar: A case report and literature review. Int Endod J 43(8): 714-722.

This work is licensed under Creative Commons Attribution 4.0 License DOI: 10.19080/ADOH.2018.09.555768
46. Mushtaq M, Farooq R, Rashid A, Robbani I (2011) Spiral computed tomographic evaluation and endodontic management of a mandibular first molar with three distal canals. J Conserv Dent 14(2): 196-198.

47. Garg AK, Tewari RK, Agrawal N, Akhtar SH (2011) Endodontic management of three-rooted mandibular second molar with the aid of spiral computed tomography: A case report. ENDO (Lond Engl) 5: 215-221.

48. Kakar S, Gupta S (2011) Endodontic treatment of permanent mandibular molar with 3 distal canals. Endodontology 91-93.

49. Jain S (2011) Mandibular first molar with three distal canals. Journal of Conservative Dentistry 14: 438-439.

50. Bhardwaj V, Garg N (2011) Mandibular first molar with multiple canals - Report of three cases. International Journal of Clincal Dental Science 2: $72-75$.

51. Silha RE (1968) Paralleling long cone techic. Dental Radiography and Photography 41: 3-19.

52. Patel S (2009) New dimensions in endodontic imaging: Part 2. Cone beam computed tomography. International Endodontic Journal 42(6): 463-475.

53. Spili P, Parashos P, Messer HH (2005) The impact of instrument fracture on outcome of endodontic treatment. J Endod 31(12): 845-850.

54. Hülsmann M (1990) Removal of silver cones and fractured instruments using the Canal Finder System. Journal of Endodontics 16(12): 596600.

55. Castellucci A (2003) Magnification in endodontics: The use of the operating microscope. Practical Periodontics and Aesthetic Dentistry 15(5): 377-384.

56. Bahcall JK (2013) Visualization in endodontics. European Journal of General Dentistry 2(2): 96-101.

\section{Your next submission with Juniper Publishers} will reach you the below assets

- Quality Editorial service

- Swift Peer Review

- Reprints availability

- E-prints Service

- Manuscript Podcast for convenient understanding

- Global attainment for your research

- Manuscript accessibility in different formats

( Pdf, E-pub, Full Text, Audio)

- Unceasing customer service

Track the below URL for one-step submission https://juniperpublishers.com/online-submission.php 